\title{
Xenofutures: towards Design as Care-Cure
}

\author{
Rodrigo Martin Iglesias \\ Universidad de Buenos Aires | Argentina | rodrigo.martin@fadu.uba.ar \\ Cristina Voto \\ Università degli Studi di Torino | Italia | cristina.voto@unito.it \\ Rocío Agra \\ Universidad Nacional de La Matanza | Argentina | ragra@unlam.edu.ar
}

\begin{abstract}
This paper synthesizes several years of research in the field of the theory of architecture and design, and undergraduate and graduate teaching. Specifically, it is a work that reflects on how architecture and design should face the most important phenomena of our present and near future. These phenomena refer to environmental, technological and anthropological aspects, and the strategies to cope with them, involving alter-native design thinking, fiction and practice in which futurabilities and futurizations depart from the displacement generated by post-utopian visions based on dissidence and subalternity. This is what we call Xenofutures, a design for curing-caring a damaged world.
\end{abstract}

Keywords: Design Fiction; Futurization; Futurability; Dissident Design; Xenofutures.

\section{INTRODUCCIÓN}

En este documento se sintetizan varios años de investigación en el campo de la teoría de la arquitectura y el diseño, y su posterior enseñanza de grado y de posgrado. Específicamente, es un trabajo que reflexiona sobre cómo la arquitectura y el diseño deben enfrentarse a los tres fenómenos paradigmáticos más importantes de nuestro presente y futuro próximo. Paradigmas como cosas con las que pensamos, más que como cosas en las que pensamos (Agamben, 2008), o en otras palabras, importa qué ideas usamos para pensar en otras ideas (Strathern, 1992). Estos fenómenos se refieren a aspectos ambientales, tecnológicos y antropológicos, y a las estrategias para hacerles frente, que implican un pensamiento y una práctica de diseño alter-nativos en los que las futurabilidades y las futurizaciones se alejan del desplazamiento generado por las visiones post-utópicas basadas en la disidencia y la subalternidad.

Mientras escribimos estas páginas la pandemia debida a COVID-19 se está extendiendo. Nos damos cuenta de que no es el momento de hacer predicciones y que para un análisis exhaustivo de los fenómenos que estamos sufriendo se requiere una buena dosis de distancia histórica. Todo lo que sabemos ahora es que el virus SARS-CoV-2 es extremadamente contagioso, que todavía no hay una cura efectiva, que no hay un sistema de salud que pueda curar a todas las personas infectadas y que la única manera de limitar la circulación del virus, hoy como en el pasado, cuando no sabíamos lo que era un virus, es limitar la circulación y el contacto de los seres humanos. Lo que sí sabemos, y de lo que no tenemos ninguna duda, es que nos encontramos inmersos en una colosal infraestructura tecnológica de comunicaciones que es totalmente asimétrica respecto a la inestable infraestructura tecnológica de los sistemas de salud. Esta asimetría se ha constituido en un poderoso motor para la transmisión del virus.

El distanciamiento social parece coincidir con el reconocimiento de nuestra interdependencia a escala mundial. A medida que nos retiramos a nuestros espacios vitales, que ahora son esferas de relativo aislamiento (para los privilegiados que los tienen), el virus, por otra parte, cruza rápidamente las fronteras de cualquier territorio nacional y conduce al cierre de casi todas las fronteras. ¿Cuáles pueden ser las consecuencias de esta pandemia si pensamos en nuestras responsabilidades éticas profesionales en relación al diseño y uso de los espacios privados y públicos, y en la profunda reciprocidad que organiza nuestro tejido social? La epidemia cambia drásticamente el significado del espacio, no hay duda: durante la emergencia sanitaria estamos experimentando cómo mantener la distancia de y con los que nos rodean. La distancia en la era viral puede convertirse en afección (frente a la infección) como un espacio de descompresión del contagio cuyos límites oscilan entre el cuidado y la curación. Una recuperación del afecto como guía y objetivo, en contra de la afectación que llena las revistas de diseño y arquitectura de las últimas décadas. Un diseño como reparación, un diseño de afectos frente a un diseño afectado (diseño de efectos), quizás priorizando la afectividad a la efectividad por primera vez en siglos.

\section{DIAGNÓSTICO}

Desde el punto de vista tecnológico estamos pensando desde el concepto de postdigital, un concepto inspirado 
en un trabajo de Nicholas Negroponte (1998) donde ya afirma que "la revolución digital ha terminado". Lo postdigital puede ser visto como modelo epocal, pero como en el posthumanismo, por ejemplo, la comprensión de lo postdigital no tiene como objetivo describir una vida después de la digital, sino que trata de describir la oportunidad de explorar las consecuencias de la digitalidad. Si bien la era informática ha mejorado la capacidad humana con prótesis atractivas e inusuales, el pensamiento postdigital puede proporcionar un marco con el que es posible examinar y comprender esta mejora. Siguiendo a Negroponte, no hay duda de que hemos estado viviendo en la era digital durante mucho tiempo, en la medida en que nuestra cultura, infraestructura y economía lo permiten. Pero también que cambios verdaderamente sorprendentes ocurrirán en otros lugares, en nuestra forma de vida y en la forma en que nos manejamos colectivamente en este planeta (1998).

Además del amplio alcance que ha tenido en el discurso artístico, la noción de postdigital describe la exploración de nuestra relación con la era de la información como el paradigma dominante en una época de mezcla global, economías entrelazadas, certeza demográfica y fronteras planetarias, por ejemplo en la obra de Berry (2014). En este sentido, Mel Alexenberg (2011) define el arte postdigital como obras que abordan la humanización del arte en su conjunto, las tecnologías postdigitales a través de la interacción entre los sistemas digitales, biológicos, culturales y espirituales, entre el ciberespacio y el espacio real, entre los medios incorporados y la realidad mixta en la comunicación social y física, entre la alta tecnología y las experiencias de alto contacto, entre las experiencias de los medios visuales, hápticos, auditivos y cinestésicos, entre la realidad virtual y la realidad aumentada, entre las raíces y la globalización. Obras de arte creadas con medios alternativos mediante la participación, la interacción y la colaboración, en las que se redefine el papel del artista (arquitecto o diseñador).

Por otro lado, desde el punto de vista ambiental, ya no hay duda de que vivimos en un contexto de transformaciones a nivel planetario y que éstas son consecuencia del impacto de las actividades humanas en la Tierra. Está claro que si no cambiamos las formas en que extraemos recursos primarios, producimos y consumimos cosas y alimentos, y gestionamos los residuos, nos dirigiremos hacia una extinción masiva. La humanidad está perdiendo la capacidad de controlar los efectos que está teniendo. Ya no es suficiente con detener el comportamiento negativo o tener una relación sostenible con el medio ambiente. Por esta razón, para pensar en el futuro elegimos hablar de Chthuluceno en lugar del Antropoceno. Donna Haraway (2016) dice que el Antropoceno será corto, que se trata más un evento fronterizo que un evento de epocal, similar al límite $\mathrm{K} / \mathrm{Pg}$ (la extinción masiva del Cretácico-Paleoceno). Y se pregunta si es posible que la brevedad de este evento fronterizo Antropoceno / Capitaloceno / Plantacionceno se deba al hecho de que entidades multiespecies, incluidos los seres humanos, forjaron en el tiempo poderosas alianzas con los poderes generadores del Chthuluceno, para provocar el resurgimiento y la curación parcial frente a la pérdida irreversible, de modo que los antiguos y los nuevos creadores de mundos pudieran echar raíces.
En este sentido, la tierra del actual Chthuluceno es simbiótica, no autopoiética, no se cierra sobre sí misma, no está completa. "El individualismo limitado (o neoliberal) enmendado por la autopoiesis no es lo suficientemente bueno, ni en sentido figurado ni científico; nos lleva por caminos mortales. El realismo agencial y la intra-acción de Barad se convierten en sentido común, y quizás en un salvavidas para los viajeros de la Tierra." (Haraway, 2016: 34). Simultáneamente, al negarse a reducir la urgencia de la tierra a un sistema abstracto de destrucción causal, Anna Tsing (2015) argumenta que la precariedad (el fracaso de las promesas mentirosas del progreso moderno) caracteriza la vida y la muerte de todas las criaturas terrestres en estos tiempos. Ella busca prácticas contaminadas y no determinantes, inconclusas y continuas de vivir en ruinas. Ella muestra cómo importa qué historias cuentan las historias como una práctica de cuidado y pensamiento. "Si la mejor manera de contar la diversidad contaminada es a través de un torrente de historias problemáticas, entonces es hora de hacer que ese torrente forme parte de nuestras prácticas de conocimiento" (Tsing, 2015).

En continuidad con los dos puntos anteriores, desde un punto de vista antropológico, establecemos la necesidad de pensar la arquitectura y el diseño en relación con una corporeidad y subjetividad cibernética. Un ciborg es simultáneamente un organismo cibernético, un híbrido de máquina y organismo, una criatura de realidad social vivida y una criatura de ficción. Un ciborg, por otra parte, no requiere una identidad estable y esencialista (Haraway, 1991). Podemos afirmar que los vínculos físicos que la humanidad tiene con las tecnologías más básicas ya nos han convertido en ciborgs. En este sentido, la pregunta de Haraway que debemos trasladar a la arquitectura y el diseño es: "¿cuándo los cambios de grado se convierten en cambios de especie, y cuáles son los efectos de la situación biocultural, biotecnológica, biopolítica e histórica de las personas (no del hombre) en relación con los efectos de los ensamblajes de otras especies y otras fuerzas bióticas/abióticas, y combinados con ellas?". El ciborg de Haraway pide una metáfora no esencial, semiótica, capaz de unir todas las coaliciones políticas en planos de afinidades. Pide una reconstrucción de la identidad, ya no dictada por el naturalismo y la taxonomía, sino por la afinidad, en la que los individuos pueden construir sus propios grupos por elección. De esta manera, los grupos podrían construir una especie de identidad postmoderna a partir de la alteridad, la diferencia y la especificidad como forma de contrarrestar las tradiciones occidentales de identificación exclusiva.

Finalmente, añadimos un cuarto tema a tener en cuenta, que introduce aspectos sociales y geopolíticos en lo anterior, a partir de la reflexión sobre cómo pensar los escenarios futuros desde el diseño conjetural y ficcional basado en la disidencia y la subalternidad desde la crisis de las hegemonías culturales y los colonialismos. Es lo que hemos llamado Futuros Disidentes y Xenofuturos. A continuación, desarrollamos estos aspectos desde un enfoque teórico, específicamente en el campo de la arquitectura y el diseño, aunque obviamente utilizando como base las experiencias pedagógicas y de diseño que hemos llevado a cabo en los últimos años. 


\section{TERAPÉUTICA}

Según la paleoantropología, la posibilidad de fabricar herramientas, esa posibilidad que hoy llamaríamos diseño, era un rasgo que caracterizaba originalmente a los homínidos de la especie Homo Erectus y que el Homo Sapiens ha asumido de manera singular gracias a nuestra capacidad de proyectar usos, funcionalidades y aplicaciones. En esta línea de pensamiento, el arqueólogo André Leroi-Gorhan (1993) afirmó que ya en aquella fabricación original convergieron dos usos supuestos y previstos: el esperado de la herramienta una vez terminada y el esperado de la acción que debe realizar la herramienta. El instrumento sería, así entendido, el fin de una acción, el de su fabricación y el medio de otra, el de su utilización. Siguiendo este razonamiento, se puede afirmar que lo que se espera del instrumento está en el centro de la producción del propio instrumento. En este sentido, producir también requiere pensar en los efectos, los deseados y/o posibles, en términos de un deseo de hacer-hacer. Esto es lo que queremos decir cuando hablamos de diseño.

Reconocer la importancia de la planificación y la imaginación cuando se diseña algo también estaba entre los intereses de Karl Marx, quien en el Volumen I de El Capital declaró que "lo que distingue al peor arquitecto de la mejor de las abejas es esto, que el arquitecto levanta su estructura en la imaginación antes de erigirla en la realidad" (1977: 344). Sin embargo, casi dos siglos después, según Franco Berardi (2017), las condiciones sociales y productivas actuales que marcan el capitalismo contemporáneo son precisamente la separación entre la planificación y la imaginación en lo que respecta a las funciones productivas socialmente asignadas $y$ diferenciadas. Berardi encuentra en las especificidades actuales de esta separación no sólo un dilema decisivo de nuestro contexto contemporáneo, sino también un punto de fuerza que puede reabrir lo posible del diseño, su poder fáctico. Haciendo hincapié en el tipo de acto productivo más que en el sujeto que lo realiza, Berardi entiende que es clave para superar la fragmentación del trabajo cognitivo si queremos hacer viable una apuesta por una sociedad creativa sin explotación, extracción o apropiación privada de lo producido socialmente.

En esta crítica de la separación contemporánea, que se remonta a los Manuscritos de Marx de 1844, la inclusión del diseño es significativa. De hecho, vivimos en un mundo profundamente condicionado por el conocimiento del diseño: Los sistemas de información y transporte, el gobierno de los flujos, la logística, la agronomía y la explotación rural, la genética, las finanzas, el urbanismo y los algoritmos son la columna vertebral de una matriz de diseño y planificación que en la última mitad del siglo pasado ha ampliado su exploración hacia los procesos y sistemas de información, desde las grandes entidades hasta las atómicas y moleculares. Podría decirse que no es una forma común en la que el diseño se presenta, pero sí subyace en esta definición una posible torsión creativa, incluso artística, de sí misma.

En este sentido, cabe destacar el uso de la expresión virtualidades que utiliza Latour porque permite pensar que hay una virtualidad en los materiales que participan y configuran las virtualidades extendidas, las de usos potenciales, las de futuros. Porque, como escribió Etienne
Souriau, "si esta mesa está físicamente hecha por el carpintero, todavía está por hacer en lo que respecta al filósofo o al artista". Descubren lo que falta, en un proceso que reconoce hitos y aperturas. Cuando Umberto Eco (2011) hablaba de objetos insuperables (como la cuchara o el libro) se refería exclusivamente a la funcionalidad consciente de estos objetos; cuando Otl Aicher hablaba de la dificultad de los arquitectos para comprender que el concepto de edificio debe incluir el uso y no sólo la construcción y el acabado se refería a la definición funcional de las cosas (1991: 269). Casi complementando estas aperturas, Souriau permite ampliar ese panorama para incorporar usos heterodoxos, interpretaciones, reconfiguraciones en tanta posibilidad siempre presente, siempre disponible. No se agotan por pertenecer a dimensiones heterogéneas, a otros modos de existencia.

En estas páginas se entiende por futuro aquella figuración que pretende superar la noción de futuro desde su dimensión exclusivamente teleológica. Aquí vale la pena seguir también a Souriau, quien en primer lugar busca distanciar el futuro de una condición enigmática pero también de su consideración en términos de causa final. No es algo que pueda ser, en términos de un acto potencial, sino algo que es de una cierta manera, es decir, el futuro: "la consumación virtual que completa el movimiento de este presente inclinado hacia el futuro, de ese futuro que cae en el presente" (1943:179). El futuro es un poder que nunca se cumple o se completa y que permite que los actos se cumplan y se completen. El futuro es la posibilidad justo antes de que surja; es la virtualidad de esa consumación. "El acontecimiento por venir es llamado y capturado, luego liberado y referido al pasado por esa forma constante, por ese "y después", por ese "y después", cuya esencia debe ser localizada, no en el instante, sino entre dos (piense en esta expresión: el intermedio, el intervalo, lo intermedio), en el inter-mundo, entre el instante que parte y el que viene" (1943:180). El futuro es ese intervalo que nace del encuentro entre dos fuerzas, una forma de nombrar el hecho de la posibilidad de que haya apoyos, propensiones, apegos, arrebatos, precipitaciones, aterrizajes. Es la forma en que las condiciones, los proyectos, las posibilidades, existen como una virtualidad de los acontecimientos. Continuando con este razonamiento, la futurización y la futurabilidad se refieren a las formas en que nos vinculamos con la futuridad. Si la primera se define por la planificación, en términos de un acto en el futuro; la segunda se entiende a través de transiciones y viajes, un poder que no cierra su definición.

Tal vez las formas de aproximación al mundo y a la invención mencionadas anteriormente sean una forma válida de renovar nuestras ideas sobre las futurizaciones, las futurabilidades y las virtualidades. Así aparece el diseño, "el punto de articulación entre lo artístico y lo ingenieril" (Berardi, 2017). Surge como un campo de problematización y exploración de los vínculos contemporáneos entre proyectos y descubrimientos. Los materiales y los conocimientos, las futurizaciones de las que participan, las improvisaciones que propician, se convierten en una zona decisiva en la producción social de vínculos abiertos con los futuros. Un campo para explorar la inventiva. 
Partamos entonces de una afirmación de Arturo Escobar, "el diseño genera las estructuras de la posibilidad humana" (2017:58), para repensar su forma de vincularse con los futuros como una redefinición de las condiciones de lo posible. El diseño se convierte así en un aporte metodológico o, en palabras de Bruno Latour: "No hay ni un fabricante, ni un propietario, ni un creador del que se pueda decir que domine los materiales; o, al menos, se introduce una nueva incertidumbre respecto a lo que se va a construir, así como quién es responsable de la aparición de las virtualidades de los materiales que se manejan" (2005: 8). Las relaciones sociales, las formas institucionales, las economías políticas, las infraestructuras y los objetos de diseño están literalmente vaciando el planeta de futuro a través de sus incalculables impactos sociales y ambientales, y cabe preguntarse si los diseñadores han sido capaces de comprender profundamente el desastre causado por la economía de hiperconsumo tardocapitalista actual. A nuestro juicio, una parte del riesgo apocalíptico que hoy sobrevuela el planeta y una parte de un vínculo patológico con el futuro capaz de hacer imposible el propio futuro, corresponden al diseño.

Según Escobar, "el diseño es ontológico porque cada objeto, herramienta, servicio o incluso relato en el que está involucrado crea formas particulares de ser, conocer y hacer" (2017:47). El diseño es una forma de vincularse con la virtualidad de los acontecimientos que, al tiempo que los provoca, busca explorarlos e inscribirlos. ¿Podemos, como propone el filósofo español Amador Fernández Savater, hackear los códigos que organizan hegemónicamente las cosas, sus usos, sus circulaciones, sus modificaciones? (Savater, 2016). ¿Qué tendencias encontraríamos donde laten las infraestructuras? ¿Qué pasaría si siguiéramos los consejos de los acuñadores del concepto de Diseño Crítico, Anthony Dunne y Fiona Raby, para quienes el papel del diseño puede ser "facilitar las visiones y no tanto definirlas, ser un catalizador más que una fuente?" (2013: 9). Elaborar preguntas que vinculen materialidades, fabricaciones, usos, ética, es discutir una política de diseño como el núcleo sensible de nuestros vínculos con el futuro.

Si asumimos que el objetivo del diseño es fabricar no sólo el objeto (el servicio, la idea) sino su mundo alrededor y que "cada objeto, herramienta, servicio o incluso narrativa en la que el diseño está involucrado crea formas particulares de ser, conocer y hacer" (Escobar, 2017: 47), es posible pensar que, a través de la invención de objetos, infraestructuras y prácticas, el diseño modula el tiempo. Es protagonista de la producción de una semántica social que incluye y propicia, excluye y hace imposible, los vínculos con los futuros. En nuestros términos, el diseño es un componente de las futurizaciones y un vector de las futurabilidades. Una práctica en la que los futuros y las futurizaciones no se desactivan mutuamente, y que puede articular una dialéctica entre proyecto y camino. Porque si diseñar es mantener "una conversación sobre las posibilidades" (Escobar, 2017: 203), el juego abierto de lo factible es una estrategia que revela la decisión y su contingencia, así como la multiplicidad productiva del mundo.

Como afirma Escobar (2017: 120), en el último decenio "han surgido importantes tendencias en el mundo del diseño que tratan de reorientar su práctica desde el significado tradicional, vinculado a la producción de objetos, el cambio tecnológico, el individuo y el mercado, visto y dirigido por profesionales en la cúspide de su experiencia, hacia una forma de ver el diseño como algo centrado en el usuario, situado, interactivo, colaborativo, participativo y centrado en la experiencia y la producción de la vida misma". Algo similar indican Dunne y Raby cuando se refieren a la aparición del diseño crítico (2013: 34). Diversos grupos, colectivos y organizaciones de todo tipo se orientan hacia formas de diseño colaborativo y formas de colaboración diseñadas, propiciando un panorama de rearticulación de las creaciones, el conocimiento, la imaginación y la vida que no se somete exclusivamente a un proyecto de valorización monetaria; incluso, más en general, que busca no someterse a la utopía como proyecto a realizar.

\section{TERAPÉUTICA}

El reto es crear vínculos de la justicia post-utópica con los futuros mediante la "creación de ámbitos sistemáticos en los que se puedan redefinir las definiciones y las normas para hacer visibles las interdependencias y los compromisos (o su ausencia)" (Escobar, 2017: 212). Esto atestigua el cambio de un diseño centrado en la futurización a otro centrado en la futurabilización, un desplazamiento que invita a producir cambios sensatos en cuanto a las figuras de la transformación social y cultural, y a abrir las vías por las que estas prácticas creativas se posicionan en cuanto al devenir y construyen lazos de futurización. No hay un diseño final, no hay una figura final. En este sentido, las prácticas de diseño pueden asumir una lógica de atención a lo afectivoefectivo, que las políticas utópicas no consideraron.

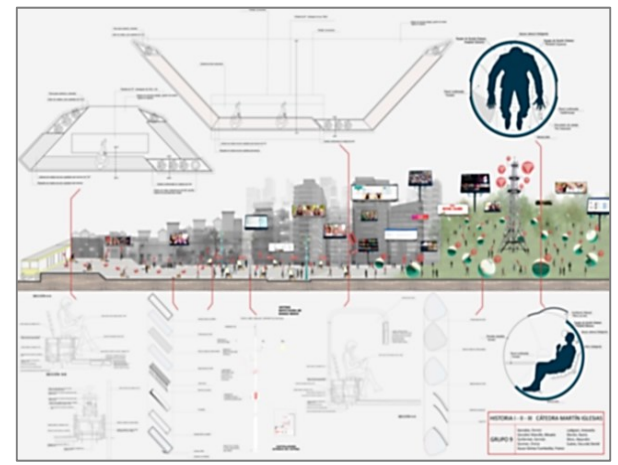

Figura 1: Gonzalez, More, Lodigiani, Guillermet, Guzman, Guzzo, Gonzalez, Mantei, Suarez; 2019

Teniendo en cuenta estas potencialidades post-utópicas del diseño, su capacidad de abrir nuevos horizontes, de contrarrestar el avance de una narrativa hegemónica para dejar espacio a una imaginación de las diferencias, hemos querido diseñar ejercicios para la puesta en práctica de un pensamiento hacia la futurabilización. Estos ejercicios se presentaron en diferentes contextos académicos en el marco de la enseñanza pública de la arquitectura en Buenos Aires (Figs. 1, 2, 3). En primer lugar se invitó a los participantes a elegir un espacio de pensamiento disidente según sus propias experiencias, donde por disidencia se recuperara más el sentido de disentir que el de estar en desacuerdo en la construcción 
de relaciones diversas. Es decir, cada participante tuvo la libertad de elegir el campo de la futurabilidad de su diseño de acuerdo a la construcción de diversas relaciones de imaginación y proyección, ya sea desde el punto de vista de clase, género, raza, edad, corporalidad, etc. A partir de la comprensión de este espacio disidente, se pidió a los participantes que detectaran un lugar común que se relacionara con la disidencia elegida y que luego procediesen a ficcionar este lugar común en un futuro posible (futurible), a partir de la disidencia.

El entrelazamiento del lugar común con la propuesta ficticia revela un cierto parentesco con las operaciones predicativas, operaciones que surgen de un vínculo de similitud, para pasar de un "ser como" a un "ser", un vínculo performativo con el que imaginar nuevos futuros, nuevos caminos semánticos, materiales y sensibles. Desde un punto de vista metodológico hemos utilizado herramientas como la traducción intersemiótica, la paracronía narrativa y visual, o la investigación tropológica (Voto y Martin Iglesias, 2019) para lograr que estas ficciones, futurizaciones y/o futuribles según el caso, logren apartarse de las visiones estereotípicas y hegemónicas del futuro. Además, en todos los casos se ofrecieron referencias bibliográficas y videográficas alternativas, disidentes o decoloniales. Estrategias que no dejan de lado el uso de la ironía o el absurdo como motores de desplazamiento figurativo.

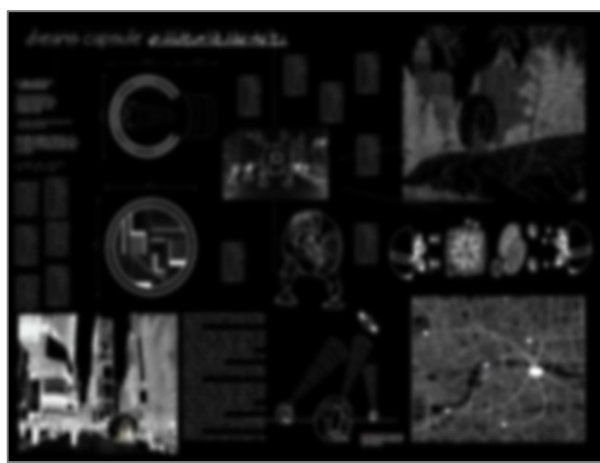

Figura 2: Curti, Galvan, Chua lurcovich, Coronel Caceres, Cortiñas, Valls Renjifo, lapparelli, Cibeira Meza, Ciovich; 2019.

A partir del anterior diagnóstico de época referido al contexto del Antropoceno/Capitaloceno/Plantationceno, a la circunstancia tecnológica post-digital y a nuestra condición de ciborgs del Chuthuluceno, hemos propuesto un marco teórico y unas estrategias de diseño que en conjunto se convierten en nuevas con-figuraciones donde el diseño puede ser un componente fundamental de las futurizaciones y un vector de futurabilidades. Para ilustrar estas potencialidades tomamos como caso digno de mención y representativo de estas estrategias el proyecto El Ombú Caminante (Fig. 3) realizado por estudiantes de Arquitectura de la Universidad Nacional de La Matanza en Argentina. El caso refleja el enfoque post-utópico que desarrollamos en este artículo en contrapunto, por ejemplo, con la Walking City de Archigram (1964). Obviamente no pretendemos integrar o sintetizar todas las referencias, tácticas y especulaciones teorizantes en un solo ejemplo, así como tampoco pretendemos que los ejercicios ofrezcan soluciones directas a los fenómenos enumerados en la primera parte. En un artículo fundamentalmente teórico, el caso sirve para manifestar de qué modo una serie de ideas conectadas en red (que pueden parecer caóticas) terminan condensando en visiones-narraciones exploradoras de mundos posibles alternativos (incluso contrafácticos) a partir de las posibilidades performativas del diseño.

Si bien es claro que no anticipamos específicamente la situación pandémica actual, consideramos que las conclusiones generales y las propuestas siguen siendo válidas, o incluso han confirmado ser necesarias. El ombú (Phytolacca dioica) es un árbol vernáculo centenario cuyas raíces tienen un sistema reticular extendido y cuya clasificación escapa a las taxonomías botánicas. El proyecto se basa en la evocación de dos enormes ombúes urbanos recientemente talados y conecta su presencia-ausencia con las memorias colectivas de las multiespecies (humanas - no-humanas) locales. De este modo, los estudiantes detectaron redes invisibles de experiencias y afectos relacionadas con cada ombú y las hicieron visibles en términos de vectores de futuro. Una reconstrucción de las relaciones temporales futuropresente-pasado que contrasta con el ímpetu de proyección futurizante tecnocrática, antropocéntrica y universalista de nuestra contemporaneidad.

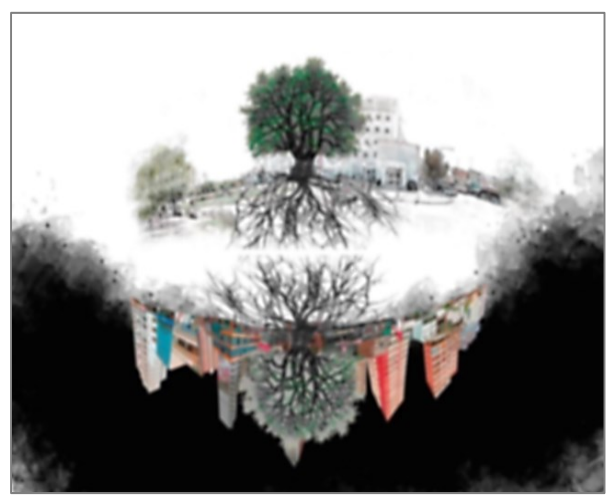

Figura 3: Acosta, Vega, Carenzo, Petkovsek; 2018.

Estas estrategias de diseño de la futurización funcionan como una terapia (del griego therapeia: cuidado) que busca la cura y el cuidado, teniendo en cuenta los afectos-efectos involucrados. Desde la propuesta inicial de un pensamiento tentacular (Haraway, 2016) se avanza hacia un pensamiento radical (en el sentido más etimológico, del latín radix) que cuida-cura como conectividad holobiomática-semiótica entre especies y entre historias. En este sentido, El Ombú Caminante cuida la memoria colectiva del lugar como holobionte (Margulis, 1990), como una entidad formada por la asociación de diferentes especies que dan lugar a unidades semioecológicas. La propuesta de un diseño como cura y cuidado se opone a la de un diseño que hace-deshace mundos (demiúrgico) y abre la posibilidad de hacer crecer colectivamente miríadas de Futuros Disidentes o Xenofuturos como construcciones ficcionales especulativas que permitan generar un suelo fértil no sólo para el futuro del diseño sino, sobre todo, para el diseño de futuros alter-nativos. 


\section{REFERENCIAS}

Agamben, G. (2008) "Che cos'è un paradigma?", Signatura rerum. Sul metodo, Torino, Bollati Boringhieri.

Alexemberg, M. (2011) The Future of Art in a Postdigital Age: From Hellenistic to Hebraic Consciousness. Second Edition. Intellect Books Exeter, UK

Berardi, F. (2017) Futurability : the age of impotence and the horizon of possibility. London ; Brooklyn: Verso.

Berry, D. M. (2014) "Thinking Postdigital Aesthetics: Art, Computation and Design". Postdigital Aesthetics. David M. Berry, Michael Dieter, Eds. Pages 1-11. Springer Nature Switzerland.

Dunne, A. and F. Raby (2013) Speculative Everything: Design, Fiction and Social Dreaming. The MIT Press.

Eco, U. (2011) This is Not the End of the Book. A conversation curated by Jean-Philippe de Tonnac. London: Harvill Secker.

Escobar, A. (2017) Autonomía y diseño. La realización de 10 comunal. Translation: Designs for the Pluriverse. Radical Interdependence, Autonomy, and the Making of Worlds. Duke University Press. 2018.

Fernández-Savater, A. (2016) De la autonomía a lo común. Entrevista a Christian Laval y Pierre Dardot. Revista Diferencia(s). №2. Año 2. Mayo 2016. Argentina.

Haraway, D. J. (1991) "A Cyborg Manifesto: Science, Technology, and Socialist-Feminism in the Late Twentieth Century". Simians, cyborgs, and women: the reinvention of nature. New York: Routledge. pp. 149-182.

Haraway, D. J. (2016) Staying with the Trouble: Making Kin in the Chthulucene, Durham, Duke University Press.
Latour, B. (2005) Reassembling the Social - An Introduction to Actor-Network-Theory. Oxford: Oxford University Press.

Leroi-Gourhan, A. (1993). Gesture and Speech. Cambridge, Massachusetts \& London: MIT Press.

Margulis, L. (1990) "Words as Battle Cries: Symbiogenesis and the New Field of Endocytobiology". BioScience 40 (9): 673

Marx, K. (1977) Capital. Vol. 1. New York: Knopf Doubleday. Fowkes, Ben, translator.

Negroponte, N. (1998) "Beyond Digital". WIRED, Issue 6.12, December.

Otl, A. (1991) Analog und Digital : Schriften zur Philosophie des Machens. Berlin: Wilhelm Ernst \& Sohn Verlag fur Architektur und technische Wissenschaften.

Souriau, É. (1943) Les différents modes d'existence, Paris, Presses Universitaires de France. (Reprinted in 2009, also by PUF, with an introduction by Isabelle Stengers and Bruno Latour.)

Strathern, M. (1992), "The Decomposition of an Event". Cultural Anthropology, 7: 244-254.

Tsing, A. L. (2015) The Mushroom at the End of the World: On the Possibility of Life in Capitalism Ruins. Princeton: Princeton University Press.

Voto, C y Martin Iglesias, R (2019) "Tropological Based Research. An exercise in the application of figuration to the construction of research problems". Proceedings of the 14th World Congress of Semiotics. AIS-IASS. 9-13 September. Buenos Aires. 